\title{
The role of host miRNAs on Mycobacterium tuberculosis
}

\author{
Ava Behrouzi ${ }^{1}$, Marjan Alimohammadi ${ }^{1}$, Amir Hossein Nafari ${ }^{1}$, Mohammad Hadi Yousefi ${ }^{1}$, Farhad Riazi Rad ${ }^{2}$, \\ Farzam Vaziri ${ }^{1}$ and Seyed Davar Siadat ${ }^{1 *}$
}

\begin{abstract}
MicroRNAs are non-coding RNAs, playing an important role in regulating many biological pathways, such as innate immune response against various infections. Different studies confirm that many miRNAs act as important regulators in developing a strategy for the survival of Mycobacterium tuberculosis in the host cell. On the other hand, an innate immune response is one of the important aspects of host defense against Mycobacterium. Considering the importance of miRNAs during tuberculosis infection, we focused on studies that performed on the role of various miRNAs related to pathogenic bacteria, M. tuberculosis in the host. Also, we have introduced important miRNAs that can be used as a biomarker for the detection of Mycobacterium.
\end{abstract}

Keywords: Mycobacterium tuberculosis, miRNA, Biomarker

\section{Introduction}

Nowadays, the broadness of infections caused by Mycobacterium tuberculosis (M. tuberculosis), and the mechanism of contracting tuberculosis (TB) is not well understood. It is estimated that 2 billion people worldwide are infected with $M$. tuberculosis, among those, $10 \%$ are active $M$. tuberculosis carriers, which can be the cause of 1.4 million annual deaths. Approximately, 5$10 \%$ of people infected with $\mathrm{TB}$, are active carriers through their lifetime [1]. Most of the people are asymptomatic, known as Latent tuberculosis infection (LTBI), which is detectable only by shreds of evidence of immunological test to mycobacteria proteins, such as pure protein, Mtb and purified protein derivative (PPD), and they lack clinical signs and symptoms of active disease [2]. The World Health Organization (WHO) estimates that nearly a third of the world's the population are positive for the PPD test [3]. This vast reservoir consists of people with LTBI infection as a source of illness that can lead to re-activation of the disease, especially in developing countries with high rates of tuberculosis infection. The risk of TB re-activation, among those with LTBI, is estimated in $10 \%$ of immunocompromised patients.

\footnotetext{
* Correspondence: siadat@pasteur.ac.ir

${ }^{1}$ Department of Mycobacteriology and Pulmonary Research, Microbiology

Research center (MRC), Pasteur Institute of Iran, Tehran, Iran

Full list of author information is available at the end of the article
}

Immunity weakness due to infections like HIV increases the risk of the disease up to $10 \%$ per year, and $50 \%$ throughout the lifetime $[4,5]$. This latency may depend on Mtb strain and host immune response [6]. The use of immune inhibitors, for example, using anti-TNF- $\alpha$ in rheumatoid arthritis patients or people with Acquired Immune Deficiency Syndrome (HIV) may lead latent bacteria to reactivate [7]. Currently, the attenuated strain of Mycobacterium bovis (M. bovis), Calmette-Guérin (BCG) is used as a vaccine against $\mathrm{TB}$, which is extremely ineffective [8]. Nowadays, the prevalence of this illness has declined through serious human efforts in research and medical care, although the occurrence of multi-drug-resistant (MDR) and extensive drug resistance (XDR) strain is increasing, and reports on the emergence of totally drug-resistant strains (TDR) have been documented [9]. The initial diagnosis of TB infection is required to control the spreading of $\mathrm{TB}$ and antimicrobial therapy against mycobacterial infections. The standard method involves the growth of microorganisms in a selective medium that normally requires a period of 3 to 12 weeks [10]. The preparation of smear from sputum has low sensitivity, and although evaluations based on PCR and immunological tests are rapid diagnostic methods [11-15], the existence of false positive and negative results make it unreliable. Therefore, there is an increasing need for new biomarkers or new diagnostic

(c) The Author(s). 2019 Open Access This article is distributed under the terms of the Creative Commons Attribution 4.0 International License (http://creativecommons.org/licenses/by/4.0/), which permits unrestricted use, distribution, and 
methods for TB diagnosis. Recently, microRNAs (miRNA) have been introduced as new diagnostic biomarkers that are widely involved in several cases such as cancer, heart disease, pregnancy, diabetes, psoriasis and many infectious diseases [16, 17]. Determining the physiological properties of miRNAs in immunity leads to the development of miRNA-based tests and treatments. Twenty-four years after the discovery of the first miRNA, the medical applications of mRNAs in infectious diseases has begun [18]. On the other hand, the importance of epigenetic changes as part of the pathogenesis of infectious disease increases our understanding of this matter [19]. Many microorganisms, including $M$. tuberculosis, induce epigenetic changes during infection [20]. Changes in histone posttranslational modification (PTM), DNA methylation and miRNAs, all play an important role in response to an infection. The discovery of sequences of 22-nucleotide RNA, as an inhibitor for the expression of proteincoding genes, was made by Ambros et al. [21], and it was first discovered in nematodes, and then hundreds of RNA molecules in size of 20-24 nucleotides were discovered in viruses, plants, animals, and humans in the next decades. These small single-strand transcripts RNA molecules can regulate gene expression, and known as microRNAs, and have led to a change in our understanding of the regulation of gene expression. miRNA binds to complementary sequences in $3^{\prime}$ untranslated region of messenger transcripts (mRNA) and prevent the translation process [22]. Each miRNA may be an inhibitor for several genes, and an mRNA can be targeted by several miRNAs [23-25]. Although studies on miRNAs are still relatively elementary, it has been shown that miRNAs are the key interfaces of gene expression, there are about 2558 human miRNAs, and these miRNAs are regulated for expression of $60 \%$ of proteincoding genes [26]. MiRNAs are the main regulator of cell differentiation and cell functions, as well as modulators in most cellular functions, including innate and acquired immune systems [27, 28]. For example, acquired immune responses, B cell differentiation, antibody production, T cell development, and function are controlled by miRNAs [29], and many studies describe the role of mammalian miRNAs in response to bacterial infections [30]. M. tuberculosis is an intracellular pathogen and can survive within the host macrophages. Macrophages are one of the most important cells in innate immune responses that can produce antimicrobial responses, such as antimicrobial peptides, hydrolases, toxic reactive oxygen, and nitro-intermediates [31]. Survival possibility of Mtb in such antimicrobial environments is very significant, and many studies have suggested that Mtb can modulate cellular function [32]. On the other hand, many studies reported that several cellular processes are regulated by eukaryotic miRNAs [22, 33]. Now, it has been determined that these processes are one of the important strategies of pathogenic bacteria for intracellular survival [34]. Pathogens exploit hosted miRNAs to eliminate immune responses [35-43]. In this article, we briefly reviewed the expression and role of various miRNAs, during infection with $M$. tuberculosis. Nowadays, due to the importance of miRNA role in the pathogenesis of tuberculosis, many types of research have focused on its practical aspects, although several researchers have explored new dimensions of miRNA effects in pathogenesis, to identify a biomarker for diagnosis of tuberculosis. Given the importance of this issue and the importance of gaining much more information from the researches on the subject of miRNA and its relation with facilitate survive of tuberculosis, the reading of such articles could have an intense involvement in performing prospective investigations.

\section{The role of miRNAs in TB infection}

M. tuberculosis is an ancient organism that has been coordinated with its human host, so it has been adapted to macrophage in the host cell for survival [44]. To date, little is known about how the macrophage immune response changes during tuberculosis infection by host miRNAs, which is the first phagocyte immune response in pulmonary microenvironments relative to $M$. tuberculosis [44]. To ensure survival and proliferation, pathogenic bacteria manipulate a wide range of host cellular pathways and functions [45]. The regulation of miRNA expression by infection due to bacterial pathogens, as soon as infection occurs, is as an essential part of the host response to infection, as well as a new molecular strategy for regulating host cell pathways by bacteria. While macrophages are target cells for Mycobacterium infection but are not affected by miRNAs, during infection. The critical point of the inherent and acquired immune responses is dendritic cells that can activate and polarize the topical $\mathrm{T}$ cell responses, regulated by miRNAs [8]. miRNAs play an essential role in regulating the primary function of macrophages, dendritic cells, and Natural Killer Cells (NKCs) [46, 47]. Many studies indicate a change in the gene expression in macrophage and NKC, due to latent and active $\mathrm{TB}$, and also in healthy individuals, compared to those with TB [48-50]. miRNAs regulate the gene expression changes and variation in cellular compositions. Several miRNAs regulate $\mathrm{T}$ cell differentiation and their function $[43,51]$. Bin et al. showed that the activation pathway of the intrinsic macrophages could change regulation, through several miRNAs (Fig. 1).

Further, they showed that $M$. tuberculosis modifies miR-26a, miR132 and other host miRNAs, attenuating immune responses to ensure survival. They also showed that miR-132 and miR-29a typically act as negative 


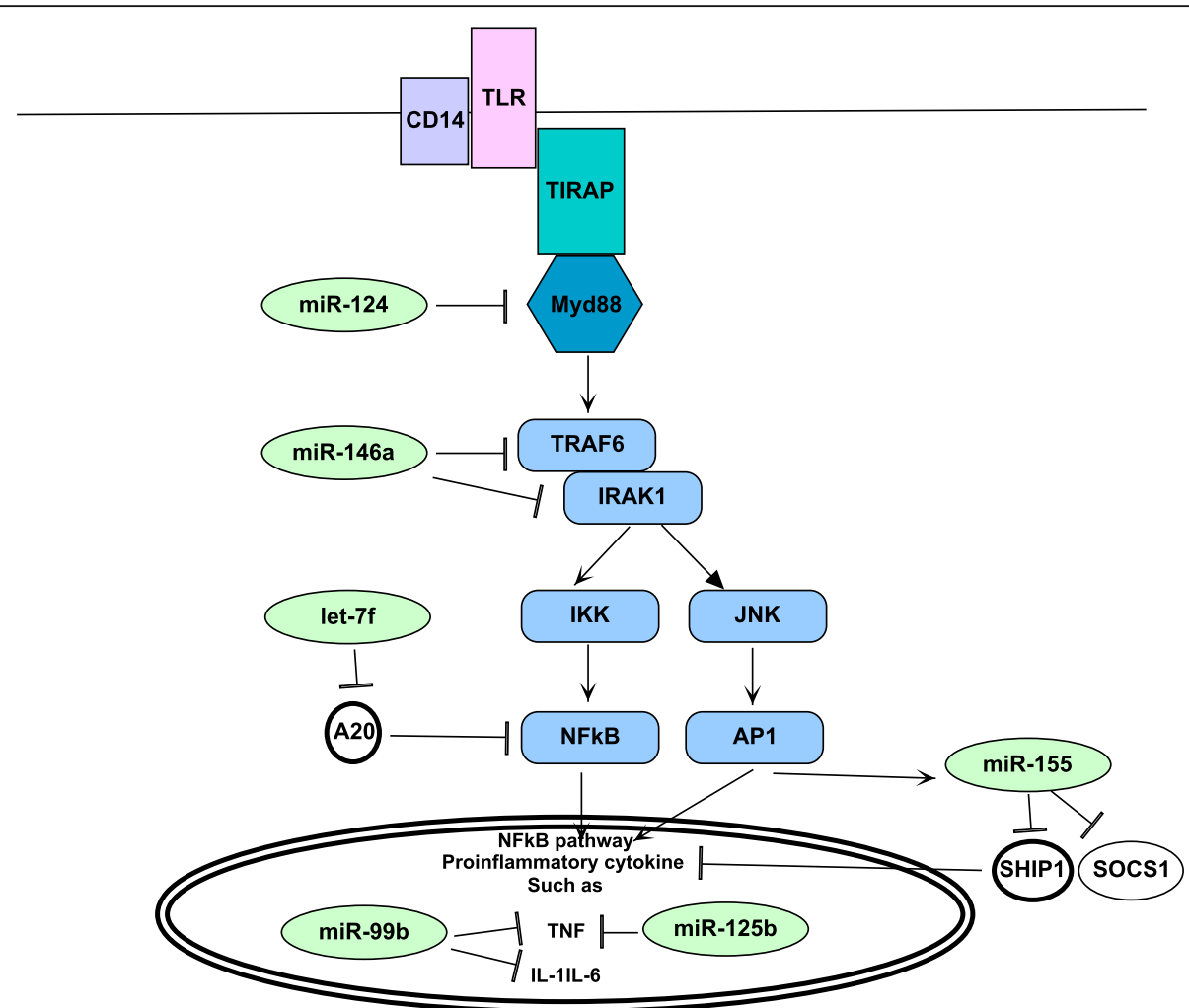

Fig. 1 MiRNAs involved in activation of the immune response and macrophage defense, during M. tuberculosis infection

regulators for macrophage function via interferon gamma. In the case of pulmonary TB, the induction of these two miRNAs in alveolar macrophages limits the immune response and degenerates the alveolar space [52]. On the other hand, previous studies have shown that miR-361-5p is relatively similar to the amount of bleomycin-induced fibrosis in the mouse lung, and may be involved in understanding the mechanisms of lung injury and fibrosis [53]. Yuhua et al. showed for the first time that high levels of miR-361 were expressed in the serum of patients with TB, compared with the healthy individuals, and it can be speculated that this reflects lung injury due to TB infection, although the associated mechanism is unclear (Table 1) [54].

\section{miRNA-29, miRNA-21 and miRNA-26a}

It has been observed that the miR-29 expression increases after infection with Mycobacterium virulent species [54-56]. Similar to what has been found for listeria infection, the miR-29 expression is downregulated, in interferon gamma-producing NKC cells, as soon as the M. bovis infection occurs [57]. It should be noted that expressing and regulating miRNA is cellular contextdependent [58]. The miR-29 knockdown in mice, results in more resistance to $M$. bovis infection and $M$. tuberculosis [57], suggesting that miR-29 induction in the $\mathrm{T}$ cell during the infection, facilitates bacterial virulence. Another study showed that upregulation of miR-29 inhibits the interferon-gamma expression [57]. miR-29 causes inhibition of interferon-gamma and excessive miR-29 may change latent TB to an active TB [57]. In a study, miR-29 was found to be increased in $\mathrm{T}$ cells of TB patients, compared with LTBI and negative control [59].

In contrast, kleinsteuber et al. showed a decrease in miR-29 in CD4 T cell of TB patients, compared to LTBI

Table 1 MiRNAs and its regulatory effects on genes involved in immunity against $M$. tuberculosis

\begin{tabular}{ll}
\hline MiRNAs & The role of miRNA \\
\hline MiR-29 & Inhibition of interferon gamma (IFNY) \\
MiR-21 & Reduced expression of IL-1B \\
& IL-12P3 inhibition \\
IL-10 increase inhibitory cytokine & Target TNF-a mRNA transcript \\
MiR-99b & Target TNF-a mRNA transcript \\
MiR-125 & Reduce inflammatory responses \\
MiR-155 & Target TNF-a mRNA transcript \\
MiR-144 & Inhibition of interferon gamma \\
MiR-223 & Inhibition of interferon gamma and TNF-a \\
MiR-26a & Inhibition of Interleukin 6 \\
& Polarization induction of anti-inflammatory \\
\hline
\end{tabular}


(but not in the negative control group) [60]. Fu et al. also investigated the expression of 1223 miRNAs on pooled serum samples, from TB patients. Meanwhile, an increase in miR-29 expression was observed in sputum specimens [54]. A similar group examined the pattern of miRNA expression in sputum and confirmed the difference in reported appearance [56]. Wu and colleagues showed that Mycobacterium is an inducer of miR-21 expression, leading to weakening of the activation of the macrophages and Th1-dependent immunity [61]. Although the exact mechanism for regulating the $\mathrm{Bcl} 2$ expression by miR-21 is unknown, inhibition of miR-21 induces IL-12 production and induces anti-mycobacterial responses, and miR-21 may be considered as an effective strategy for mycobacterium to escape the host immune responses and establish chronic infection [62]. Bin et al. showed that TB is an inducer of miR-26a, and inducing this miRNA leads to a reduction in the P300 expression, which in turn leads to a reduction in the transcription of interferon-gamma-inducing genes and the response of macrophages to this crucial cytokine. Interferon-gamma repression in CD4, CD8 T cells by tuberculosis may be a survival strategy in the host cell [52].

\section{miRNA-125b and miR-155}

In a study, Rajaram et al. showed a link between virulence of Mycobacterium species and TNF- $\alpha$ production, and a difference in expression between miR-155 and miR-125b [63]. miR-125b directly targets mRNA of TNF- $\alpha$ and results in associated destabilization. Murugesan et al. showed that miR-125b is attached to $3^{\prime}-$ UTR of TNF- $\alpha$ transcript and caused downregulation [64]. On the other hand, the enhancer of sustainability is KB2-Ras2 that is NFkB signaling inhibitor in human macrophages, thus reduces the inflammatory responses [65]. miR-55 can be the inducer of TNF- $\alpha$ synthesis by targeting SHIP-1, which is a negative regulator of the P13K / AKT route. Munigesan et al. found that Mycobacterium smegmatis (SmegLM) is an inducer of the miR-155 expression in macrophages, which reduces the SHIP1 expression and thus increases TNF mRNA stability and TNF production. Their studies showed that miRNAs were essential regulators for the production of TNF during mycobacterial infection [57]. Interestingly, the induction of cells with lipomannan, components of the bacterial cell wall, caused by virulent TB strain or M. smegmatis nonvirulent strain, also lead to opposite effects on the synthesis of TNF- $\alpha$, in a way that the lipomannan produced by TB is an inhibitor of TNF- $\alpha$ synthesis, while the lipomannan provided by $M$. smegmatis is the inducer of TNF- $\alpha$ expression. This phenomenon is related to the balance between the expression of miR-155 and miR-125b $[63,66]$. In another study, transfection of murine macrophages with miR-155 resulted in a decrease in mycobacterium intracellular survival [67]. It is possible that the miR-155 varies the antimicrobial activity by regulating two processes, including the macrophage apoptosis [68] and autophagy [69] for immunity. Another study, by Wang et al., showed that miR-155 upregulation could determine TB infection in mouse macrophages by activating the autophagy pathway [69], and inducing autophagy through inhibition of the negative regulator Rheb and other components of the signaling pathway mTOR [69, 70]. Another study reported that M. tuberculosis causes high levels of miR-155 and lower levels of miR-125b, while M. smegmatis is an inducer of low levels of miR-155 and high levels of miR-125b. The induction of miR-155 expression in active or harmful TB infection is still uncertain. Kumar et al. showed that in mouse macrophages, M. tuberculosis could modulate the cell's environment in its favor, and that act is due to the miR-155 expression through the EAST-6 protein, which correlates with the virulence of bacteria [67]. The mutant strain of ESAT-6 TB has a lower induction of miR-155 in macrophages than wild type [67]. Upregulation of miR-155 can activate the AKT pathway, involve for the survival of $M$. tuberculosis in macrophages, and it is the inhibitor of the cytokineinduced pro-inflammatory IL-6 [67]. Given the increase in the synthesis of TNF- $\alpha$ through SHIP1 pathway [63], and considering some negative effects, miR-155 function in the survival of mycobacteria within the host cell remains unclear. Despite these issues, it has been shown that mycobacteria have a mechanism to deal with the negative effects of miR-155, which help mycobacterium to survival in the host, for example, the lipomannan from the cell wall of TBF- $\alpha$ is an inhibitor of TNF- $\alpha$ synthesis and is contrast with the effect of upregulation of miR-155 [63]. On the other hand, TB is an inducer of miR-125b, which directly targets mRNA of TNF. Therefor miR125-b can also reduce TNF synthesis and balance the effects of upregulation of miR-155.

\section{miRNA-144 and miRNA-146a}

Overexpression of miR-144 has been observed in patients with active TB [71]. Cheng et al. showed that miR-144 is significantly altered in PBMC of patients with active TB [72]. Yuhua et al. showed that miRNAs, mostly upregulated in the serum of patients with $\mathrm{TB}$, while only seven miRNAs are downregulated, although the miR-144 expression in this group did not confirm by q-PCR [54]. miR-144 can target Janus / kinase (JAK) signal transducer genes, MAPK and TLR signaling pathways, and Cyto-Cyto receptor interactions. miR-144 is also the inhibitor of the production of TNF- $\alpha$ and interferon gamma, both playing an important role in protecting immunity. Different findings have been reported about miR-144 expression, Wang et al, indicate the increase of the miR-144 expression in TB patients (only in 
comparison with the negative control group) [7], while no expression difference was found in miR-144 by others [73]. Since miR-144 is an important factor in T cells in TB patients, such diverse and confusing results can be due to heterogeneity in PBMC samples [74]. In addition, miRNA array shows a reduction in the miR144 expression in CD4 $\mathrm{T}$ cell in TB patients, compared to LTBI, but the results from the analysis of pooled samples with q-PCR did not confirm this result [62]. miR-223 acts like miR-146a, which modulates the IKK- $\alpha$ subunit of NFkB and regulates inflammatory responses in phagocytic monocytes. miR-223 is significantly upregulated in the blood and lung of patients with TB [75]. Also, upregulated miR-223 is the inhibitor of CCl3, CXCL2, and IL6 , and it has recently been reported that miR-223 deletion causes hypersensitivity to TB infection [76].

Mycobacterial infections in macrophages significantly induce the miR-146a expression; that expression level is a dose-dependent [77]. This miRNA involves two critical factors in the TLR / NFkB signaling pathway, including IRAK1 and TRAF6; the increase in the expression of this miRNA during the infection, affects the TLR / NF-kB pathways, and subsequently reduces the cytokines TNF$\alpha$, IL-1b, IL-6, and chemokine MCP-1. In particular, M. tuberculosis seems to use mannose receptors to escape the bactericidal effects of superoxide [78].

\section{Other miRNAs}

The ability of $M$. tuberculosis to survive and develop a disease is associated with the escape from the host defense and immune mechanisms. In particular, tuberculosis has a significant potential for survival within the hostile environments of macrophage. $M$. tuberculosis has expanded many pathways to inhibit macrophage antimicrobial effects for intracellular survival [32]. One of these strategies is the ability to prevent phagosome maturation and other measures to avoid autophagy and to escape from the phagosome environment [79-81]. Autophagy has recently been introduced as a mechanism for killing pathogens. Autophagy is an intracellular process involved in self-digestion or self-eating, in which cytoplasmic components are transmitted to the lysosome and are ultimately degenerated [82]. The pathways associated with autophagy are challenging to regulate at post-transcriptional levels and are well described, but the involvement of miRNAs inactivating or inhibiting autophagy during TB infection is largely unknown [30]. Some reports show the induction of the miR-33 expression in THP-1 and HEK-293 cells, leading to inhibition of pathways involved in autophagy, and also resulting in reprogramming of host lipid metabolism for intracellular survival and TB stability [30]. Recent studies have also shown that miR-33 leads to inhibition of autophagia through inhibition of possible autophagy factors, such as
ATG5, ATG12, LC3B, and transcription factors, such as FOXO3 and TFEB (as an important regulatory factor in regulating transcription of the genes associated with autophagy) [75].

Kim et al. [75] stated that miR-125a-3p was upregulated in macrophages infected with TB, which is related to the inhibition of autophagy by targeting UVRAG. Guo et al. [83] also showed an increase in the miR-144$3 p$ expression that is an inducer of the ATG4a gene (a gene involved in autophagy inhibition). Another study suggested that overexpression of miR-23a-5p inhibited autophobic activity [9]. Another study demonstrated the downregulation of miR-3619-5p by BCG, leading to upregulation of cathepsin S (CTSS) (Lysosomal Cysteine Protease), and the inhibition of the CTSS expression can enhance autophagy. Chen et al., showed that the miR$30 \mathrm{a}$ is a negative regulator of autophagy that was upregulated in macrophages infected with $\mathrm{TB}$, although they believed that increase in the miR-30a expression alone could not be the leading cause of inhibition of autophagy, speculating that this miRNA is part of a complex mechanism that is regulated by many molecules, associated with autophagy (Fig. 2) [84].

\section{miRNAs as a biomarker}

miRNAs are widely considered as non-invasive prognosis and prognostic markers. Many of studies have used miRNAs, as diagnostic biomarkers for early detection of many cancers, such as breast cancer [85], lung carcinoma [86, 87], and colorectal cancer. Considering the new findings, concerning miRNAs, and also the fact that miRNAs are stable in the serum [88]. Therefore, they can be considered as a good biomarker [89, 90].

Recently, the role of miRNAs in host-pathogen responses has been considered. Human miRNAs may play an essential role in viral proliferation, limitation of antiviral responses, inhibition of apoptosis and induction of cell growth [91]. Also, miRNAs play a significant role in immune response and inflammatory responses in bacterial infections [57, 92]. Diagnosis of TB infection is severe, compared to many other bacterial infections [44]. One of the effective methods for controlling the spread of TB is the early diagnosis of the disease. Nowadays, many diagnostic tests do not distinguish between active TB and LTBI, and thus miRNAs can be reliable, as potential diagnostic biomarkers [93]. Although the suitable biomarker has not yet been identified, [94], recently, several types of miRNA as a biomarker have been investigated in the diagnosis of TB $[72,95,96]$, using PBMC and serum [72] of patients with TB.

Interestingly, an active link between the expression of miRNA and gene expression has been found [30]. Wang et al. [97] showed that miR-31 is significantly reduced in patients with $\mathrm{TB}$, compared to the healthy children, and 


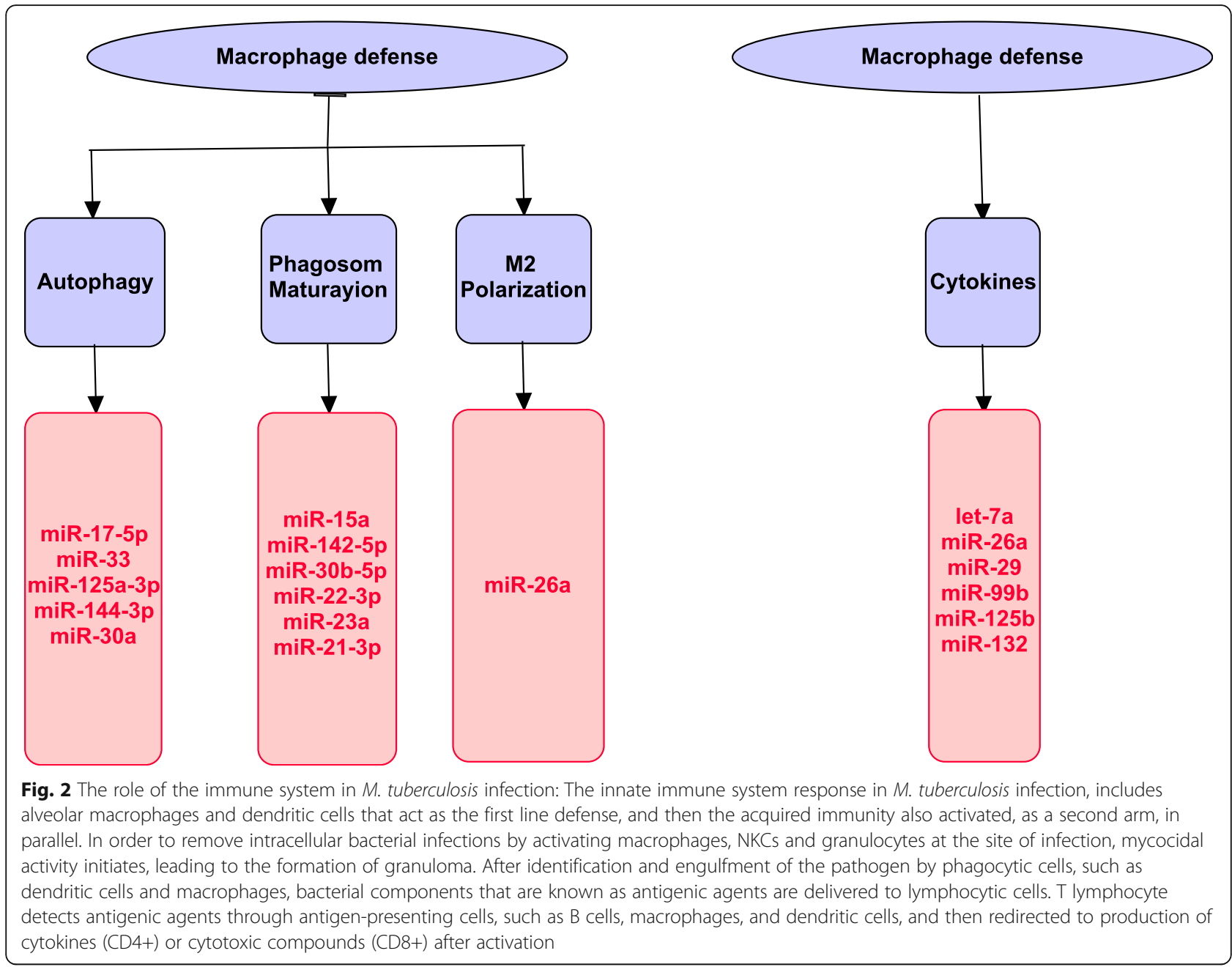

besides, this study indicates that expression of this miRNA has a negative correlation with the levels of IL6 , TNF- $\alpha$, and IFN. They also argued that the expression profile of miRNAs varies, among many individuals and it is not gendered specific or clinical phenotypedependent, although they were able to distinguish the expression of an active TB group from the latent TB group, using the 17miRNA predicted by the SVM method, most (12 out of 17) upregulated in patients with active TB [7]. Barry et al. (2015) also showed that miR-93 as miRNA is suitable for normalizing miRNA levels in TB patients [98]. Latorre et al. also introduced nine miRNAs with different expressions, in patients with active $\mathrm{TB}$, compared to healthy individuals or people with LTBI.

MiR-361-5p, miR-889, and miR-576-3p also showed good ability to detect TB infection from other microbial infections. Information gathered from these three miRNAs showed a significant difference between TB infections and three groups of microbial infections [53]. Miotto et al. also distinguished a cluster of
15miRNA, among children with TB and healthy controls, and introduced miR-192 as the only candidate, showing significant differences in adults and children [92]. On the other hand, some studies suggest that miRNA may also be useful in the development of TB-resistant strains, for example, Ren et al. (2015) [99] showed 142 different miRNAs are expressed in individuals with MDR TB, not seen in sensitive strains.

All of these studies have significantly contributed to the presentation of various miRNAs as biomarker candidates for TB diagnosis, but so far no miRNA has been included as a biomarker, and many factors are relevant in this regard, including the heterogeneity of data. For example, data from Zhou and colleagues revealed a lot of inconsistencies with previous studies; for instance, they showed that miR-155 is downregulated in people with TB [100]. While Wu et al. [96] showed miR-155 in the PBMC of patients with active TB was upregulated. On the other hand, Zhou et al. showed that miR-141, miR-32, miR-29b were overexpressed in the TB group, 
while the expression level of miR-144 varied in previous studies, for example, Wang et al., showed upregulation of miR-144 in TB patients. [7] While Wu and colleagues report the downregulation [96], Zhou et al. [100] did not see expression changes and this controversy in the results is due to different conditions and the use of different protocols. Although, Ueberberg et al. [101] reported that miR-22, miR-25, miR-19, miR-365, miR-4835p, miR-590 and miR-885-5p are suitable biomarkers, because of being validated in two different studies. Other studies that led to introducing this factor as an appropriate biomarker were lacking a statistical significance, as well as using a small group size, which requires further studies to validate the potential diagnostic marker.

\section{Conclusion}

TB is one of the deadliest diseases in the world, which is very difficult to eradicate because of its ability to survive in macrophages. Intracellular bacteria, such as $M$. tuberculosis can survive and multiply in phagocytic cells and generally can regulate the host defense system to survive and replicate through various pathways. One of these pathways is the change in the miRNA expression, to change the immune response and ultimately facilitate the establishment of infection in the host cell. In recent years, the role of miRNAs as regulatory factors in the inherent and acquired immune responses to $\mathrm{TB}$ infection has been widely considered. MicroRNAs have been studied extensively and have an important ability to regulate gene expression. miRNAs affect many important processes and are important regulators of the immune system (Fig. 3).

On the other hand, many studies have confirmed the different expressions of miRNAs in people with active $\mathrm{TB}$ and those with latent infection, and these findings provide new insights for the use of miRNAs as diagnostic biomarkers. Although there are some limitations in this regard, including the fact that miRNAs are not entirely gene-specific, many of their characteristics have made them suitable biomarker candidates. One of the important properties that make them more suitable

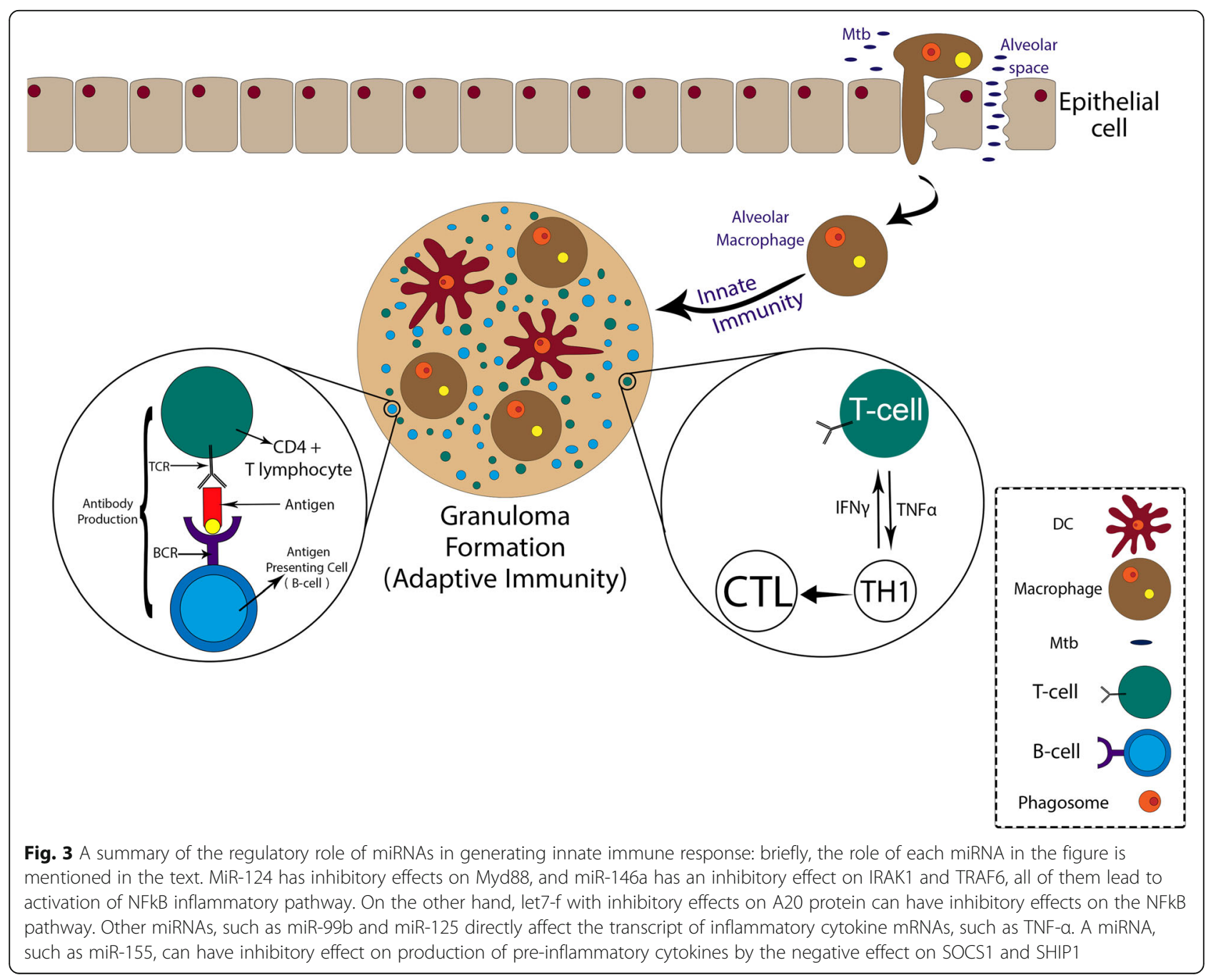


candidates is their high stability in body fluids and their relationship to many diseases that can be used as biomarkers for the classification of infectious diseases, as well as for therapeutic purposes. On the other hand, the involvement of miRNAs in autophagy processes has opened a new window to scientists. All of these findings can provide valuable information on the diagnosis, treatment, and design of appropriate vaccines against infections caused by $M$. tuberculosis. Ultimately, the potential for the use of miRNAs as biomarkers in the treatment of TB requires further extensive studies in this field.

\section{Acknowledgements}

We thank all the colleagues in the Department of Mycobacteriology and Pulmonary Research.

\section{Authors'contributions}

$A B, M A$ and FR prepare collection of main data. AN and MY design the Figures and table. SS and FV edit the main manuscript text. All authors read and approved the final manuscript.

\section{Availability of data and materials}

Data sharing not applicable to this article as no datasets were generated or analysed during the current study.

\section{Ethics approval and consent to participate}

Not applicable

\section{Consent for publication}

Not applicable

\section{Competing interests}

The authors declare that they have no competing interests.

\section{Author details}

'Department of Mycobacteriology and Pulmonary Research, Microbiology Research center (MRC), Pasteur Institute of Iran, Tehran, Iran. ${ }^{2}$ Department of Immunology, Pasteur Institute of Iran, Tehran, Iran.

Received: 15 March 2019 Accepted: 17 July 2019

Published online: 08 November 2019

\section{References}

1. Kaufmann SH, McMichael AJ. Annulling a dangerous liaison: vaccination strategies against AIDS and tuberculosis. Nat Med. 2005;11:S33-44.

2. Barry CE 3rd, Boshoff HI, Dartois V, Dick T, Ehrt S, Flynn J, et al. The spectrum of latent tuberculosis: rethinking the biology and intervention strategies. Nature reviews. Microbiology. 2009;7:845-55.

3. Corbett EL, Watt CJ, Walker N, Maher D, Williams BG, Raviglione MC, et al. The growing burden of tuberculosis: global trends and interactions with the HIV epidemic. Arch Intern Med. 2003;163:1009-21.

4. Selwyn PA, Alcabes P, Hartel D, Buono D, Schoenbaum EE, Klein RS, et al. Clinical manifestations and predictors of disease progression in drug users with human immunodeficiency virus infection. N Engl J Med. 1992:327:1697-703.

5. Verver S, Warren RM, Munch Z, Vynnycky E, van Helden PD, Richardson M, et al. Transmission of tuberculosis in a high incidence urban community in South Africa. Int J Epidemiol. 2004;33:351-7.

6. Casanova JL, Abel L. Genetic dissection of immunity to mycobacteria: the human model. Annu Rev Immunol. 2002:20:581-620.

7. Wang C, Yang S, Sun G, Tang X, Lu S, Neyrolles O, et al. Comparative miRNA expression profiles in individuals with latent and active tuberculosis. PLoS One. 2011;6:e25832.

8. Mehta MD, Liu PT. microRNAs in mycobacterial disease: friend or foe? Front Genet. 2014;5:231.

9. Velayati AA, Masjedi MR, Farnia P, Tabarsi P, Ghanavi J, ZiaZarifi AH, et al. Emergence of new forms of totally drug-resistant tuberculosis bacilli: super extensively drugresistant tuberculosis or totally drug-resistant strains in Iran. Chest. 2009;136:420-5.

10. Golyshevskaia VI, Korneev AA, Chernousova LN, Selina LG, Kazarova TA, Grishina TD, et al. New microbiological Techniques in diagnosis oftuberculosis. Probl Tuberk. 1996:(6):22-5.

11. Cheah ES, Malkin J, Free RC, Lee SM, Perera N, Woltmann G, et al. A twotube combined TaqMan/SYBR green assay to identify mycobacteria and detect single global lineage-defining polymorphisms in Mycobacterium tuberculosis. J Mol Diagn. 2010;12:250-6.

12. Elzi L, Steffen I, Furrer H, Fehr J, Cavassini M, Hirschel B, et al. Improved sensitivity of an interferon-gamma release assay (T-SPOT.TB) in combination with tuberculin skin test for the diagnosis of latent tuberculosis in the presence of HIV co-infection. BMC Infect Dis. 2011;11:319.

13. Foongladda S, Pholwat S, Eampokalap B, Kiratisin P, Sutthent R. Multi-probe real-time PCR identification of common Mycobacterium species in blood culture broth. J Mol Diagn. 2009;11:42-8.

14. Mansoor N, Scriba TJ, de Kock M, Tameris M, Abel B, Keyser A, et al. HIV-1 infection in infants severely impairs the immune response induced by Bacille Calmette-Guerin vaccine. J Infect Dis. 2009;199:982-90.

15. Ramos JM, Robledano C, Masia M, Belda S, Padilla S, Rodriguez JC, et al. Contribution of interferon gamma release assays testing to the diagnosis of latent tuberculosis infection in HIV-infected patients: a comparison of QuantiFERON-TB Gold In Tube, T-SPOT.TB and tuberculin skin test. BMC Infect Dis. 2012;12:169.

16. Cui L, Qi Y, Li H, Ge Y, Zhao K, Qi X, et al. Serum microRNA expression profile distinguishes enterovirus 71 and coxsackievirus 16 infections in patients with hand-foot-andmouth disease. PLoS One. 2011;6:e27071.

17. Lawrie CH, Gal S, Dunlop HM, Pushkaran B, Liggins AP, Pulford K, et al. Detection of elevated levels of tumour-associated microRNAs in serum of patients with diffuse large Bcell lymphoma. Br J Haematol. 2008;141:672-5.

18. Drury RE, O'Connor D, Pollard AJ. The clinical application of MicroRNAs in infectious disease. Front Immunol. 2017;8:1182.

19. Bierne H, Hamon M, Cossart P. Epigenetics and bacterial infections. Cold Spring Harb Perspect Med. 2012;2:a010272.

20. Yaseen I, Kaur P, Nandicoori VK, Khosla S. Mycobacteria modulate host epigenetic machinery by Rv1988 methylation of a non-tail arginine of histone H3. Nat Commun. 2015;6:8922.

21. Lee $R C$, Feinbaum $R L$, Ambros $V$. The $C$. elegans heterochronic gene lin-4 encodes small RNAs with antisense complementarity to lin-14. Cell. 1993:75:843-54.

22. Bartel DP. MicroRNAs: genomics, biogenesis, mechanism, and function. Cell. 2004;116:281-97.

23. Mayr C, Hemann MT, Bartel DP. Disrupting the pairing between let-7 and Hmga2 enhances oncogenic transformation. Science (New York, NY). 2007; 315:1576-9.

24. Mendell JT, Olson EN. MicroRNAs in stress signaling and human disease. Cell. 2012;148:1172-87.

25. Pillai RS, Bhattacharyya SN, Filipowicz W. Repression of protein synthesis by miRNAs: how many mechanisms? Trends Cell Biol. 2007:17:118-26.

26. Friedman RC, Farh KK, Burge CB, Bartel DP. Most mammalian mRNAs are conserved targets of microRNAs. Genome Res. 2009:19:92-105.

27. Steiner DF, Thomas MF, Hu JK, Yang Z, Babiarz JE, Allen CD, et al. MicroRNA29 regulates T-box transcription factors and interferon-gamma production in helper T cells. Immunity. 2011;35:169-81.

28. Bazzoni F, Rossato M, Fabbri M, Gaudiosi D, MiRolo M, Mori L, et al. Induction and regulatory function of miR-9 in human monocytes and neutrophils exposed to proinflammatory signals. Proc Natl Acad Sci U S A. 2009;106:5282-7.

29. Singh Y, Kaul V, Mehra A, Chatterjee S, Tousif S, Dwivedi VP, et al. Mycobacterium tuberculosis controls microRNA-99b (miR-99b) expression in infected murine dendritic cells to modulate host immunity. J Biol Chem. 2013;288:5056-61.

30. Sabir N, Hussain $T$, Shah SZA, Peramo A, Zhao D. Zhou X miRNAs in Tuberculosis: New Avenues for Diagnosis and Host-Directed Therapy Frontiers in microbiology. 2018;9:602.

31. Fenton MJ, Vermeulen MW. Immunopathology of tuberculosis: roles of macrophages and monocytes. Infect Immun. 1996;64:683-90.

32. Ahmad S. Pathogenesis, immunology, and diagnosis of latent Mycobacterium tuberculosis infection. Clin Dev Immunol. 2011;2011:814943.

33. Giraldez AJ, Cinalli RM, Glasner ME, Enright AJ, Thomson JM, Baskerville S, et al. MicroRNAs regulate brain morphogenesis in zebrafish. Science (New York, NY). 2005;308:833-8. 
34. Das K, Garnica O, Dhandayuthapani S. Modulation of host miRNAs by intracellular bacterial pathogens. Front Cell Infect Microbiol. 2016:6:79.

35. Cameron JE, Yin Q, Fewell C, Lacey M, McBride J, Wang X, et al. Epstein-Barr virus latent membrane protein 1 induces cellular MicroRNA miR-146a, a modulator of lymphocyte signaling pathways. J Virol. 2008;82:1946-58.

36. Chinnappan M, Singh AK, Kakumani PK, Kumar G, Rooge SB, Kumari A, et al. Key elements of the RNAi pathway are regulated by hepatitis B virus replication and $\mathrm{HBx}$ acts as a viral suppressor of RNA silencing. The Biochemical journal. 2014;462:347-58.

37. Cullen BR. MicroRNAs as mediators of viral evasion of the immune system. Nat Immunol. 2013;14:205-10.

38. Ellis-Connell AL, lempridee T, Xu I, Mertz JE. Cellular microRNAs 200b and 429 regulate the Epstein-Barr virus switch between latency and lytic replication. J Virol. 2010;84:10329-43.

39. Fu YR, Liu XJ, Li XJ, Shen ZZ, Yang B, Wu CC, et al. MicroRNA miR-21 attenuates human cytomegalovirus replication in neural cells by targeting Cdc25a. J Virol. 2015;89:1070-82.

40. Grinberg M, Gilad S, Meiri E, Levy A, Isakov O, Ronen R, et al. Vaccinia virus infection suppresses the cell microRNA machinery. Arch Virol. 2012;157:1719-27.

41. Jopling $C L$, Yi M, Lancaster AM, Lemon SM, Sarnow P. Modulation of hepatitis C virus RNA abundance by a liver-specific MicroRNA. Science (New York, NY). 2005;309:1577-81.

42. Li J, Yu L, Shen Z, Li Y, Chen B, Wei W, et al. miR-34a and its novel target, NLRC5, are associated with HPV16 persistence. Infect Genet Evol. 2016:44:293-9.

43. Lui $Y L$, Tan $T L$, Woo WH, Timms $P$, Hafner $L M$, Tan $K H$, et al. Enterovirus 71 (EV71) utilise host microRNAs to mediate host immune system enhancing survival during infection. PLoS One. 2014;9:e102997.

44. Saltini C. Chemotherapy and diagnosis of tuberculosis. Respir Med. 2006; 100:2085-97.

45. Bhavsar AP, Guttman JA, Finlay BB. Manipulation of host-cell pathways by bacterial pathogens. Nature. 2007:449:827-34.

46. Bezman NA, Cedars E, Steiner DF, Blelloch R, Hesslein DG, Lanier LL. Distinct requirements of microRNAs in NK cell activation, survival, and function. J Immunol (Baltimore, Md: 1950). 2010;185:3835-46.

47. O'Connell RM, Rao DS, Chaudhuri AA, Baltimore D. Physiological and pathological roles for microRNAs in the immune system. Nat Rev Immunol. 2010;10:111-22

48. Maertzdorf J, Repsilber D, Parida SK, Stanley K, Roberts T, Black G, et al. Human gene expression profiles of susceptibility and resistance in tuberculosis. Genes Immun. 2011;12:15-22.

49. Marin ND, Paris SC, Rojas M, Garcia LF. Functional profile of CD4+ and CD8+ $T$ cells in latently infected individuals and patients with active TB. Tuberculosis (Edinburgh, Scotland). 2013;93:155-66.

50. Sharbati J, Lewin A, Kutz-Lohroff B, Kamal E, Einspanier R, Sharbati S Integrated microRNA-mRNA-analysis of human monocyte derived macrophages upon Mycobacterium avium subsp hominissuis infection. Plos one. 2011;6:e20258.

51. Du C, Liu C, Kang J, Zhao G, Ye Z, Huang S, et al. MicroRNA miR-326 regulates $\mathrm{TH}-17$ differentiation and is associated with the pathogenesis of multiple sclerosis. Nat Immunol. 2009;10:1252-9.

52. Ni B, Rajaram MV, Lafuse WP, Landes MB, Schlesinger LS. Mycobacterium tuberculosis decreases human macrophage IFN-gamma responsiveness through miR-132 and miR-26a. J Immunol (Baltimore, Md: 1950). 2014; 193:4537-47.

53. Xie T, Liang J, Guo R, Liu N, Noble PW, Jiang D. Comprehensive microRNA analysis in bleomycin-induced pulmonary fibrosis identifies multiple sites of molecular regulation. Physiol Genomics. 2011;43:479-87.

54. Fu Y, Yi Z, Wu X, Li J, Xu F. Circulating microRNAs in patients with active pulmonary tuberculosis. J Clin Microbiol. 2011;49:4246-51.

55. Rome S. Are extracellular microRNAs involved in type 2 diabetes and related pathologies? Clin Biochem. 2013;46:937-45.

56. Yi Z, Fu Y, Ji R, Li R, Guan Z. Altered microRNA signatures in sputum of patients with active pulmonary tuberculosis. PLoS One. 2012;7:e43184.

57. Ma F, Xu S, Liu X, Zhang Q, Xu X, Liu M, et al. The microRNA miR-29 controls innate and adaptive immune responses to intracellular bacterial infection by targeting interferongamma. Nat Immunol. 2011; 12:861-9.

58. Maudet C, Mano M, Eulalio A. MicroRNAs in the interaction between host and bacterial pathogens. FEBS Lett. 2014;588:4140-7.
59. Fu Y, Yi Z, Li J, Li R. Deregulated microRNAs in CD4+ T cells from individuals with latent tuberculosis versus active tuberculosis. J Cell Mol Med. 2014;18:503-13.

60. Kleinsteuber K, Heesch K, Schattling S, Kohns M, Sander-Julch C, Walzl G, et al. Decreased expression of miR-21, miR-26a, miR-29a, and miR-142-3p in CD4(+) T cells and peripheral blood from tuberculosis patients. PLoS One. 2013:8:e61609.

61. Wu Z, Lu H, Sheng J, Li L. Inductive microRNA-21 impairs anti-mycobacterial responses by targeting IL-12 and BCl-2. FEBS Lett. 2012;586:2459-67.

62. Harapan H, Fitra F, Ichsan I, Mulyadi M, Miotto P, Hasan NA, et al. The roles of microRNAs on tuberculosis infection: meaning or myth? Tuberculosis (Edinburgh, Scotland). 2013;93:596-605.

63. Rajaram MV, Ni B, Morris JD, Brooks MN, Carlson TK, Bakthavachalu B, et al. Mycobacterium tuberculosis lipomannan blocks TNF biosynthesis by regulating macrophage MAPK-activated protein kinase 2 (MK2) and microRNA miR-125b. Proc Natl Acad Sci U S A. 2011:108:17408-13.

64. Ottenhoff TH. New pathways of protective and pathological host defense to mycobacteria. Trends Microbiol. 2012;20:419-28.

65. Pennini ME, Pai RK, Schultz DC, Boom WH, Harding CV. Mycobacterium tuberculosis 19-kDa lipoprotein inhibits IFN-gamma-induced chromatin remodeling of MHC2TA by TLR2 and MAPK signaling. Journal of immunology (Baltimore, Md : 1950). 2006;176:4323-30.

66. Tili E, Michaille JJ, Cimino A, Costinean S, Dumitru CD, Adair B, et al. Modulation of miR-155 and miR-125b levels following lipopolysaccharide/TNF-alpha stimulation and their possible roles in regulating the response to endotoxin shock. J Immunol (Baltimore, Md: 1950). 2007;179:5082-9.

67. Kumar R, Halder P, Sahu SK, Kumar M, Kumari M, Jana K, et al. Identification of a novel role of ESAT-6-dependent miR-155 induction during infection of macrophages with Mycobacterium tuberculosis. Cell Microbiol. 2012;14:1620-31.

68. Ghorpade DS, Leyland R, Kurowska-Stolarska M, Patil SA, Balaji KN. MicroRNA-155 is required for Mycobacterium bovis BCG-mediated apoptosis of macrophages. Mol Cell Biol. 2012;32:2239-53.

69. Wang J, Yang K, Zhou L, Minhaowu W. Y, Zhu M, et al. MicroRNA-155 promotes autophagy to eliminate intracellular mycobacteria by targeting Rheb. PLoS Pathog. 2013;9:e1003697.

70. Wan G, Xie W, Liu Z, Xu W, Lao Y, Huang N, et al. Hypoxia-induced MIR155 is a potent autophagy inducer by targeting multiple players in the MTOR pathway. Autophagy. 2014;10:70-9.

71. WHO global tuberculosis control report 2010. Summary. Cent Eur J Public Health. 2010;18:237. https://www.ncbi.n/m.nih.gov/pubmed/21361110.

72. Liu Y, Wang X, Jiang J, Cao Z, Yang B, Cheng X. Modulation of T cell cytokine production by miR-144* with elevated expression in patients with pulmonary tuberculosis. Mol Immunol. 2011;48:1084-90.

73. Spinelli SV, Diaz A, D'Attilio L, Marchesini MM, Bogue C, Bay ML, et al. Altered microRNA expression levels in mononuclear cells of patients with pulmonary and pleural tuberculosis and their relation with components of the immune response. Mol Immunol. 2013;53:265-9.

74. Jacobsen M, Repsilber D, Gutschmidt A, Neher A, Feldmann K, Mollenkopf $\mathrm{HJ}$, et al. Candidate biomarkers for discrimination between infection and disease caused by Mycobacterium tuberculosis. Journal of molecular medicine (Berlin, Germany). 2007:85:613-21.

75. Qin Y, Wang Q, Zhou Y, Duan Y, Gao Q. Inhibition of IFN-gamma-induced nitric oxide dependent Antimycobacterial activity by miR-155 and C/ EBPbeta. Int J Mol Sci. 2016;17:535.

76. Dorhoi A, lannaccone M, Farinacci M, Fae KC, Schreiber J, Moura-Alves $P$, et al. MicroRNA-223 controls susceptibility to tuberculosis by regulating lung neutrophil recruitment. J Clin Invest. 2013;123:4836-48.

77. Li S, Yue Y, Xu W, Xiong S. MicroRNA-146a represses mycobacteria-induced inflammatory response and facilitates bacterial replication via targeting IRAK-1 and TRAF- 6. PLoS One. 2013;8:e81438.

78. Astarie-Dequeker C, N'Diaye EN, Le Cabec V, Rittig MG, Prandi J, Maridonneau-Parini I. The mannose receptor mediates uptake of pathogenic and nonpathogenic mycobacteria and bypasses bactericidal responses in human macrophages. Infect Immun. 1999;67:469-77.

79. Espert L, Beaumelle B, Vergne I. Autophagy in Mycobacterium tuberculosis and HIV infections. Front Cell Infect Microbiol. 2015;5:49.

80. Russell DG. Mycobacterium tuberculosis and the intimate discourse of a chronic infection. Immunol Rev. 2011;240:252-68.

81. Vergne I, Gilleron M, Nigou J. Manipulation of the endocytic pathway and phagocyte functions by Mycobacterium tuberculosis lipoarabinomannan. Front Cell Infect Microbiol. 2014;4:187. 
82. Lamb CA, Yoshimori T, Tooze SA. The autophagosome: origins unknown, biogenesis complex. Nature reviews. Mol Cell Biol. 2013;14:759-74.

83. Kim JK, Yuk JM, Kim SY, Kim TS, Jin HS, Yang CS, et al. MicroRNA-125a Inhibits Autophagy Activation and Antimicrobial Responses during Mycobacterial Infection. J Immunol (Baltimore, Md: 1950). 2015;194:5355-65.

84. Chen Z, Wang T, Liu Z, Zhang G, Wang J, Feng S, et al. Inhibition of autophagy by MiR-30A induced by mycobacteria tuberculosis as a possible mechanism of immune escape in human macrophages. Jpn J Infect Dis. 2015;68:420-4

85. Cortez MA, Welsh JW, Calin GA. Circulating microRNAs as noninvasive biomarkers in breast cancer. Recent results in cancer research. Fortschritte der Krebsforschung. Progres dans les recherches sur le cancer. 2012;195:151-61.

86. Chang KH, Mestdagh P, Vandesompele J, Kerin MJ, Miller N. MicroRNA expression profiling to identify and validate reference genes for relative quantification in colorectal cancer. BMC Cancer. 2010;10:173.

87. Chen $X$, Hu Z, Wang W, Ba Y, Ma L, Zhang C, et al. Identification of ten serum microRNAs from a genome-wide serum microRNA expression profile as novel noninvasive biomarkers for nonsmall cell lung cancer diagnosis. Int J Cancer. 2012;130:1620-8.

88. Chen $X$, Ba Y, Ma L, Cai X, Yin Y, Wang K, et al. Characterization of microRNAs in serum: a novel class of biomarkers for diagnosis of cancer and other diseases. Cell Res. 2008;18:997-1006.

89. Gilad S, Meiri E, Yogev Y, Benjamin S, Lebanony D, Yerushalmi N, et al. Serum microRNAs are promising novel biomarkers. PLoS One. 2008;3:e3148.

90. Mitchell PS, Parkin RK, Kroh EM, Fritz BR, Wyman SK, Pogosova-Agadjanyan EL, et al. Circulating microRNAs as stable blood-based markers for cancer detection. Proc Natl Acad Sci U S A. 2008;105:10513-8.

91. Grassmann R, Jeang KT. The roles of microRNAs in mammalian virus infection. Biochim Biophys Acta. 2008;1779:706-11.

92. Xiao B, Liu Z, Li BS, Tang B, Li W, Guo G, et al. Induction of microRNA-155 during helicobacter pylori infection and its negative regulatory role in the inflammatory response. J Infect Dis. 2009:200:916-25.

93. Miotto P, Mwangoka G, Valente IC, Norbis L, Sotgiu G, Bosu R, et al. miRNA signatures in sera of patients with active pulmonary tuberculosis. PLoS One. 2013;8:e80149

94. Walzl G, Ronacher K, Hanekom W, Scriba TJ, Zumla A. Immunological biomarkers of tuberculosis. Nat Rev Immunol. 2011;11:343-54.

95. Maertzdorf J, Weiner J 3rd, Mollenkopf HJ, Network TB, Bauer T, Prasse A, et al. Common patterns and disease-related signatures in tuberculosis and sarcoidosis. Proc Natl Acad Sci U S A. 2012;109:7853-8.

96. Wu J, Lu C, Diao N, Zhang S, Wang S, Wang F, et al. Analysis of microRNA expression profiling identifies miR-155 and miR-155* as potential diagnostic markers for active tuberculosis: a preliminary study. Hum Immunol. 2012;73:31-7.

97. Wang JX, Xu J, Han YF, Zhu YB, Zhang WJ. Diagnostic values of microRNA31 in peripheral blood mononuclear cells for pediatric pulmonary tuberculosis in Chinese patients. Genet Mol Res. 2015;14:17235-43.

98. Barry SE, Chan B, Ellis M, Yang Y, Plit ML, Guan G, et al. Identification of miR93 as a suitable miR for normalizing miRNA in plasma of tuberculosis patients. J Cell Mol Med. 2015;19:1606-13.

99. Ren N, Gao G, Sun Y, Zhang L, Wang H, Hua W, et al. MicroRNA signatures from multidrugresistant Mycobacterium tuberculosis. Mol Med Rep. 2015;12:6561-7.

100. Zhou M, Yu G, Yang X, Zhu C, Zhang Z, Zhan X. Circulating microRNAs as biomarkers for the early diagnosis of childhood tuberculosis infection. Mol Med Rep. 2016;13:4620-6.

101. Ueberberg B, Kohns M, Mayatepek E, Jacobsen M. Are microRNAs suitable biomarkers of immunity to tuberculosis? Mol Cell Pediatr. 2014;1:8.

\section{Publisher's Note}

Springer Nature remains neutral with regard to jurisdictional claims in published maps and institutional affiliations.

Ready to submit your research? Choose BMC and benefit from:
- fast, convenient online submission
- thorough peer review by experienced researchers in your field
- rapid publication on acceptance
- support for research data, including large and complex data types
- gold Open Access which fosters wider collaboration and increased citations
- maximum visibility for your research: over 100M website views per year
At BMC, research is always in progress.
Learn more biomedcentral.com/submissions

